\title{
Performance and pressure drop of CO2 absorption into task-specific and halide-free ionic liquids in a microchannel
}

\author{
Daofan $\mathrm{Ma}^{1}$, Chunying Zhu ${ }^{1}$, Taotao $\mathrm{Fu}^{1}$, Youguang $\mathrm{Ma}^{1}$, and Xigang Yuan ${ }^{1}$ \\ ${ }^{1}$ Tianjin University
}

September 24, 2021

\begin{abstract}
The gas-liquid two-phase flow pattern, absorption rate and pressure drop of $\mathrm{CO} 2$ absorbed into the aqueous solution of the taskspecific ionic liquid (1-aminopropyl-3-methylimidazole tetrafluoroborate [Apmim][BF4] and 1- hydroxyethyl-3-methylimidazole tetrafluoroborate [OHemim][BF4]) and halide-free ionic liquid 1- butyl -3-methylimidazolium methylsulfate [Bmim][CH3SO4] were investigated in a microreactor. The absorption mechanism of the three ionic liquids was analyzed employing the $13 \mathrm{C}$ NMR spectroscopy. The [Apmim][BF4] was found to have the best ability of $\mathrm{CO} 2$ capture compared to the other two ionic liquids, as chemical absorption occurred between [Apmim][BF4] and $\mathrm{CO} 2$, while only physical absorption took place between $[\mathrm{OHemim}][\mathrm{BF} 4] /[\mathrm{Bmim}][\mathrm{CH} 3 \mathrm{SO} 4]$ and $\mathrm{CO} 2$. The sequence of $\mathrm{CO} 2$ absorption rate in three ionic liquid aqueous solutions is: $[$ Apmim $][\mathrm{BF} 4]>[\mathrm{Bmim}][\mathrm{CH} 3 \mathrm{SO} 4]>[\mathrm{OHemim}][\mathrm{BF} 4]$. Furthermore, the effects of gas-liquid flow rate and ionic liquids concentration on $\mathrm{CO} 2$ absorption rate and pressure drop were studied, the pressure drop models based on various flow patterns were proposed.
\end{abstract}

\section{Hosted file}

manuscript.docx available at https://authorea.com/users/435676/articles/538535-performanceand-pressure-drop-of-co2-absorption-into-task-specific-and-halide-free-ionic-liquids-ina-microchannel 